\title{
Bullying, homofobia e violência no espaço da escola: Pensando gênero, sexualidade e práticas sociais a partir de uma pesquisa de campo ${ }^{1}$
}

\section{Bullying, homophobia and violence in school space: Thinking about gender, sexuality and social practices from a field research}

Aparecido Francisco dos Reis ${ }^{2}$

\begin{abstract}
Resumo: Considerando as situações de violência escolar, o objetivo desta pesquisa é verificar e identificar ocorrências de bullying homofóbico em escola de ensino fundamental em Campo Grande-MS. Foram utilizados métodos qualitativos de pesquisa como o trabalho de campo, observação e falas de pessoas da comunidade escolar. As situações de violência homofóbica se dão, principalmente, de forma implícita, camuflada nos discursos e nas brincadeiras entre os alunos, sempre ofendendo, discriminando e ridicularizando o homossexual. Como aparecem camufladas, as formas de agressão muitas vezes passam despercebidas no discurso tanto de professores quanto de alunos e são reproduzidas quase que sem controle algum e muitas vezes não sabendo identificar nem lidar com o problema ou justificando sua posição através de valores morais já perfeitamente interiorizados.
\end{abstract}

Palavras-chave: Bullying, homofobia, escola.

\begin{abstract}
Considering the situations of school violence, the objective of this research is to verify and identify occurrences of homophobic bullying in elementary school in Campo Grande-MS. We used qualitative research methods such as fieldwork, observation and speeches of people from the school community. The situations of homophobic violence occur mainly, implicitly, camouflaged in speeches and games between students, always offending, discriminating and ridicule the homosexual. As they appear camouflaged, forms of aggression often go unnoticed in the discourse of both teachers and students and are reproduced almost without any control and often not knowing how to identify or deal with the problem or justify their position through already perfectly internalized moral values.
\end{abstract}

Key words: Bullying, homophobia, school.

\section{Introdução}

A escola sempre se apresentou como um dos contextos institucionais de educação mais regulatórios e normativos quer ao nível do gênero, quer ao nível da sexualidade (MEYER, 2008, p. 131). Com as missões delegadas pela modernidade, tanto de transmissão e reprodução, como de fabricação do cidadão ideal (HABERMAS, 1995, p. 91), dimensões como corpo, gênero e/ou sexualidade tendem a ser vistas como assuntos delicados e raramente tratados (LOURO, 2001, p. 35; JUNQUEIRA, 2009, p. 17). Desde a década

\footnotetext{
${ }^{1}$ Este projeto recebeu financiamento do $\mathrm{CNPq}$

${ }^{2}$ Universidade Federal de Mato Grosso do Sul
} 
de noventa, o seu caráter normativo e o modelo fictício de aluno ideal (masculino, branco, de classe média, heterossexual, fisicamente eficiente) têm sido questionados, defendendo a integração de valores antidiscriminatórios nas suas políticas e práticas. O movimento de Lésbicas, Gays, Bissexuais, Transgênero, Queer e Intersexuais (LGBTQI), têm também denunciado o caráter homofóbico e heteronormativo da instituição em diversos níveis, seja o preconceito, a discriminação e a violência nas relações interpessoais, a negligência na prevenção e/ou eliminação dessa mesma violência ou um certo silenciamento de tópicos relativos à diversidade sexual e de gênero a nível curricular (JUNQUEIRA, 2009, p. 21).

Segundo Vianna (2015) o debate no Brasil, acerca dessa temática nas políticas públicas em educação foi introduzido apenas em meados da década de noventa e início dos anos 2000. Posteriormente, durante os dois mandatos de Lula na Presidência da República (2003-2010) houve uma maior abertura para a questão com projetos de formação continuada docente, enquanto política resultante dos Programas Brasil sem homofobia e Escola sem Homofobia. Essas ações deram maior "visibilidade a estas questões antes ignoradas, principalmente por serem consideradas tabus no ambiente escolar" (VIANNA, 2015 p. 802).

No entanto, a inclusão dessa temática ainda não é uma realidade em todas instituições de ensino do país. Segundo pesquisa do Instituto Nacional de Pesquisas Educacionais Anísio Teixeira (Inep) em 2011, mais da metade das escolas brasileiras que oferecem ensino médio não desenvolvem projetos sobre diversidade sexual, de gênero e de combate à homofobia.

Nesse contexto, no âmbito do Governo Federal houve investimentos na produção de ações e materiais didáticos voltados à formação docente, enfocando as questões de gênero e da diversidade sexual. A iniciativa desencadeou uma falsa polêmica em torno da adequação de se tratar desses temas no ambiente escolar, em alguns casos sob o argumento de que esses materiais seriam peças de propaganda em favor de uma determinada orientação sexual. Esta reação levou à suspensão, em 2011, da decisão de se distribuir um material produzido com este fim específico pelo Ministério da Educação ${ }^{3}$.

O debate prolongou-se nos anos seguintes, durante as discussões acerca do Plano Nacional de Educação (PNE), aprovado pela Lei 13.005/2014. Em sua versão preliminar incluía uma referência à promoção da igualdade racial, regional, de gênero e de orientação sexual entre suas diretrizes. No entanto, durante a tramitação no Congresso Nacional, o texto do PNE foi alterado e a versão final preconiza a promoção da cidadania e a erradicação de todas as formas de discriminação de maneira genérica. Em consequência disso, as referências a metas voltadas à promoção da igualdade de gênero e de orientação sexual na escola foram suprimidas também de planos estaduais e municipais em diversas localidades em razão da pressão exercida por evangélicos e católicos contrários a essa política pública. Essa aliança entre setores geralmente não ligados entre si surtiu efeito. Segundo levantamento realizado em janeiro de 2016 pela iniciativa "De Olho nos Planos",

\footnotetext{
${ }^{3}$ Segundo o G1. após protestos das bancadas religiosas no Congressso, a presidente Dilma Rousseff determinou no dia 25/05/2011 a suspensão do "kit anti-homofobia", que estava sendo elaborado pelo Ministério da Educação para distribuição nas escolas, repassando informações do ministro da Secretaria-Geral da Presidência, Gilberto Carvalho. http://g1.globo.com/educacao/noticia/2011/05/dilma-rousseff-manda-suspender-kit-anti-homofobiadiz-ministro.html. Acesso em 18/05/2018
} 
em relação aos 22 das 27 Planos Estaduais de Educação aprovados e sancionados na forma de lei, 9 não fazem qualquer referência à palavra "gênero" e 15 não explicitam o termo "gênero" nos Princípios ou Diretrizes do Plano ao citar o enfrentamento a toda forma de discriminação (DE OLHO NOS PLANOS, 2016).

Em Mato Grosso do Sul, o Plano Estadual de Educação aprovado pela Lei 4.621, de 22 de dezembro de 2014, no artigo $2^{\circ}$, inciso X contempla as questões de gênero e sexualidade na interface com outras questões como os Direitos Humanos, promoção da saúde e prevenção das DST/Aids, alcoolismo e drogas, questões étnico-raciais, geracionais e situação das pessoas com deficiência, aos menos, para os trabalhadores da educação.

Embora constasse no projeto inicial a discussão das temáticas de gênero e sexualidade foi retirada do Plano Municipal de Educação de Campo Grande. A retirada se deu numa votação na Câmara Municipal em 23/06/2015, após pressão de setores da Igreja Católica e de evangélicos, terminantemente contrários a esse debate (ZABARTO; QUEIRÓZ, 2017, p. 374).

\section{Metodologia}

A metodologia desenvolvida ao longo do trabalho de campo teve a duração de um ano, abrangendo o segundo semestre de 2015 e o primeiro semestre de 2016. O acesso ao campo foi possível devido aos contatos entre os pesquisadores e professores da escola, travados em anos anteriores, em que os autores foram convidados a realizar oficinas com alunos e professores acerca da homofobia, bullying, violência doméstica, violência contra a mulher, racismo e outros temas. Na ocasião, muitas questões referentes ao tema em epígrafe foram observadas, o que resultou, posteriormente, num trabalho de campo mais sistemático sobre o ambiente escolar. A própria direção da escola e a coordenação pedagógica consideram relevantes pesquisar essas questões, porque os assuntos sempre são abordados pelos alunos/as seja como inquirição aos professores ou ainda, na manifestação de preconceitos e outras violências simbólicas.

As turmas pesquisadas foram do $6^{\circ}$ ao $9^{\circ}$ ano do ensino fundamental do período matutino, nas aulas teóricas em sala de Artes, Geografia, Linguagens e de Educação Física. Deve-se ressaltar que a escolha se deu em razão do convite dos professores dessas disciplinas. Focar nessas turmas facilitou aprofundar o acompanhamento e observações e obter dados com certa regularidade, e as aulas de Educação Física foram especialmente importantes neste trabalho, porque são aquelas nas quais ocorrem mais frequentemente a separação entre meninos e meninas para a realização das atividades recreativas e esportivas como poderá ser visto mais adiante.

As falas dos alunos foram obtidas através de conversas informais, não sendo construído um roteiro para guiar, nem as conversas foram gravadas. Assim, durante o texto, serão comentados os resultados dessas conversas semanais com os alunos, professores e direção da escola.

O período descrito permitiu um contato mais profundo com os sujeitos do campo estudado. Para tanto, o caminho escolhido para a coleta de dados, de certo modo, teve como referência o método etnográfico. 
A etnografia é uma metodologia qualitativa de pesquisa que teve sua origem na antropologia cultural, e que se propõe a descrever e a interpretar ou explicar o que as pessoas fazem em um determinado ambiente (sala de aula, por exemplo). De acordo com SILVA ET AL (2010, p. 89) o termo etnografia tem sido usado para designar o estudo dos fenômenos sociais a partir de uma investigação em que o pesquisador participa ativamente no contexto pesquisado com o intuito de entender os significados das ações e dos comportamentos dos sujeitos que vivem e se relacionam neste ambiente. Segundo CASTRO (2011), as pesquisas do tipo etnográfico permitem que o sujeito e o pesquisador possam compartilhar experiências que partem das explicações que os sujeitos constroem sobre si que delineiam os processos vivenciados por eles, desta forma o pesquisador poderá interagir diretamente com o seu objeto de pesquisa, no intuito de aprofundar as suas percepções

O método etnográfico foi proposto por Malinowski na segunda década do século XX no livro Os Argonautas do Pacífico Ocidental (1976), publicado originalmente em 1922.

Malinowski apresenta uma preocupação em detalhar os princípios fundamentais que compõem o método de pesquisa da antropologia moderna, indicando os passos para sua execução. Entre os passos do método etnográfico, usou-se aqui a descrição dos elementos imponderáveis da vida escolar como os fenômenos cotidianos que foram observados por meio do acompanhamento contínuo das brincadeiras, comentários, conflitos, nos espaços comuns e durante as aulas. Outro ponto observado foram as palavras e expressões características da mentalidade de professores e alunos, que contribuem para a compreensão da sua visão de mundo, descobrindo os modos de pensar e sentir típicos dos sujeitos em questão.

É importante ressaltar que Malinowski rompeu com uma "antropologia de gabinete", na qual o investigador fazia suas análises a partir das informações obtidas junto a viajantes, mercadores e missionários, e inaugura um novo estilo de pesquisa pautado em um constante diálogo entre a observação participante e as descrições etnográficas. O método proposto por Malinowski compreende uma investigação aprofundada da vida nativa de modo que o etnógrafo possa compreender a organização social da vida tribal, sintetizada através da compreensão do ponto de vista nativo. A importância da obra de Malinowski fica explicitada, portanto, em seu trabalho monográfico, no qual estão expressas as possibilidades interpretativas suscitadas pelo método etnográfico.

Vários alunos, por vezes mais de um ao mesmo tempo, ficavam ao redor dos pesquisadores tanto na sala de aula, quanto no corredor da escola, e faziam perguntas, como nome, o porquê de estar ali, gosto musical, idade e o que faziam na universidade. Assim, foi necessário buscar categorias inteligíveis aos alunos, como por exemplo, falar sobre dos gostos musicais de cada um; explicar o que é uma universidade, o que se estuda e, por fim, informar claramente que a pesquisa era sobre preconceito, violência e homofobia e que as observações em sala eram necessárias para se fazer isso. 
Outra forma utilizada de manter contato com alunos foi a utilização do Facebook ${ }^{4}$, em que se pode conversar e se aproximar melhor do grupo pesquisado, facilitando as conversas no ambiente escolar.

Além disso, se garantiu que toda fala, entrevista ou anotações de campo, seriam anônimas e que os participantes seriam identificados por pseudônimo. Esse processo interativo entre os sujeitos envolvidos na pesquisa possibilita ao longo do tempo, uma relação baseada na confiança. A questão da confiança é muito importante para a pesquisa; diversos antropólogos citam a importância de conseguir ser confiável para o grupo que pesquisa, como mostra, por exemplo, Foote-Whyte (1975):

Como Doc havia suposto, ninguém perguntou a meu respeito, porém mais tarde me contou que, quando fui ao banheiro, irrompeu uma conversa excitada em italiano e ele teve que convencê-los de que eu não era um policial federal [...] fomos juntos diversas vezes ao estabelecimento de Chichi - até chegar o momento em que me atrevi a ir lá sozinho. Quando fui recebido de maneira natural e amigável senti que estava começando a ocupar um lugar em Corneville. (FOOTE-WHYTE, 1975, p.77)

Foi acertado com a direção da escola que os pesquisadores manteriam o sigilo dos nomes de cada aluno ou professor, independente do que fosse observado, ouvido ou relatado. Esse acerto foi comunicado aos alunos e os se sentiram mais confiantes e à vontade para conversar e se expressar com os pesquisadores.

\section{O bullying homofóbico - Discussão e resultados}

Nos últimos anos, tem-se utilizado a expressão bullying homofóbico como um denominador discursivo para explicar processos de preconceito, discriminação e violência homofóbica na escola (MONK, 2012, p. 190). Enquanto na literatura especializada, o bullying é geralmente definido como uma violência entre pares caracterizada por intencionalidade em magoar, repetição e poder diferencial entre os elementos envolvidos (FURLONG et al. 2010, p. 341), a sua associação à homofobia remete, como resume Junqueira, para uma força desumanizadora (2009, p. 37) contra aqueles/as que não seguem - ou se julga não seguirem - um desejo, uma identidade, estilos de vida ou práticas afetivas e/ou sexuais de matriz heterossexual. Vários estudos têm demonstrado a prevalência, as causas e as consequências do bullying homofóbico aos mais variados níveis (cf. FIPE 2009; UNESCO 2012;), salientando a necessidade de mais pesquisa e intervenção. Também no contexto brasileiro existem já alguns estudos relacionando homofobia e educação (cf. SOUZA ET AL, 2015; ROSELICRUZ, 2011; ALBUQUERQUE; WILLIANS, 2015), mas como lembram Nogueira e Oliveira (2010, p. 21), ainda existe pouco conhecimento, sobretudo acerca do que os/as jovens têm a dizer. Tem-se, contudo, criticado a opção pela designação de bullying homofóbico pelo seu essencialismo (MONK, 2012, p.193). Em primeiro lugar, o conceito parece ser incapaz de ilustrar, descrever e explicar todas as formas de violência homofóbica e, sobretudo, heteronormativa da e na escola que não podem ser confinadas a uma noção restritiva e monolítica de bullying (FORMBY, 2015, p. 627), mas podem envolver formas de violência heteronormativa ou

\footnotetext{
${ }^{4}$ Facebook.com.br
} 
institucional da escola quando invisibiliza ou negligencia o problema. (FORMBY; 2015). Como salienta PASCOE (2013, p. 2), a noção de bullying parece referir-se mais a processos circunstanciais de agressão, esquecendo-se de uma abordagem mais sistemática e estrutural sobre os processos opressivos de discriminação. Em segundo lugar, o termo bullying homofóbico parece remeter para um determinado tipo de bullying contra LGBTQIs.

Parece que basta ser-se gay ou lésbica para se sofrer bullying (MONK; 2012, 193), o que contribui para uma produção discursiva de uma identidade potencialmente negativa e em risco que não corresponde à realidade de várias pessoas LGBTQIs (Lésbicas, Gays, Transexuais, Queer e Intersexuais), a começar pelo fato dessa identidade ter que ser expressa ou, pelo menos, simbolicamente sugerida. Por estas razões, alguns/mas investigadores/as sugerem diferentes terminologias. MINTON ET AL. (2008, p. 181), por exemplo, identificam dois subtipos de bullying homofóbico: um tipo de bullying indireto, a que chamam de bullying heteronormativo, que deriva do ambiente heteronormativo da escola, isto é, onde se espera que toda a gente seja, deva ser ou goste de ser tomada como heterossexual até prova em contrário. É um subtipo de bullying menos reconhecido como tal e, por isso, raramente desafiado pelos/as educadores/as. Um outro subtipo é o bullying baseado na orientação sexual e da identidade de gênero que envolve a discriminação ativa e direta de pessoas reconhecidas como LGBTQI, e corresponde ao que habitualmente preenche o imaginário do que é o bullying homofóbico. Ainda que muitas vezes essas interseções entre gênero e sexualidade possam ser olhadas de modo analiticamente separáveis - uma coisa são expressões de feminilidade ou masculinidade, outra são os dinamismos do desejo ou conduta sexual - a questão de gênero é central na forma como o bullying é ou não acionado.

Criticando a noção de bullying pelo esquecimento da sua dimensão generificada, MEYER (2008, p. 38), em vez de bullying, propõe o termo assédio de gênero, analisando três subtipos do mesmo: violência (hetero) sexual, violência homofóbica e violência transfóbica. Por sua vez, PASCOE (2013, p. 6) relembra que o bullying homofóbico está mais relacionado com processos de socialização para a masculinidade, não tendo necessariamente como alvo uma identidade (homo)sexual. É importante não esquecer que a teorização sobre homofobia tem feito um longo caminho, que vai desde um certo abandono de posições mais intrapsíquicas até a uma compreensão dos processos de opressão contra as minorias sexuais como estruturais e sistemáticos (JUNQUEIRA; 2009, p. 45).

$\mathrm{O}$ artigo que aqui se apresenta tenta aprofundar estas questões usando um desenho de natureza qualitativa com recurso da observação em pesquisa de campo numa escola de ensino fundamental de Campo Grande - MS, buscando investigar as ocorrências de bullying direcionado aos LGBTQIs no ambiente da escola.

As quatro (4) turmas pesquisadas foram do $6^{\circ}$ ao $9^{\circ}$ ano do ensino fundamental do período matutino, em que os pesquisadores participaram das atividades na escola de duas a três vezes por semana, acompanhando aulas de Geografia, Educação Física, Língua Portuguesa e Artes a convite dos professores. Focar nestas turmas facilitou aprofundar o acompanhamento e as observações e obter dados. 
As observações foram feitas dentro das salas de aula e na quadra durante as aulas de Educação Física, com o objetivo de poder ter maior contato com o cotidiano dos alunos e assim compreender as representações e sentidos utilizados por estes na reprodução dos discursos heteronormativos e sexistas. As frequentes idas foram necessárias para que os alunos se familiarizassem com a presença dos pesquisadores e pudessem se expressar sem receios.

Nas primeiras visitas, foi recomendado pela direção da escola, que os pesquisadores entrassem na sala de aula sempre acompanhados pelo professor responsável pela disciplina, esse protocolo foi repetido por umas duas semanas até que alunos/as e demais funcionários da escola não estranhassem mais a nossa presença. Depois disso, transitávamos por toda parte da escola e o pessoal simplesmente não se incomodava com nossa presença.

Na sala de aula, tínhamos às vezes que nos sentar à frente das turmas em cadeiras para adultos. Não foi possível sentar em meio aos alunos, devido ao tamanho das carteiras da escola, adequado a crianças do sexto ano, isto é, pequena demais para aguentar um adulto. Sentar-se à frente não atrapalhou nos colocou na posição de observados pelos alunos e em todas as salas, nas primeiras semanas éramos constantemente interpelados sobre nossa presença naquele espaço, com perguntas sobre família, o trabalho na universidade, a utilidade de nossos estudos, se éramos gays, sobre qual time de coração. Esses diálogos, às vezes bastante tumultuados pelo interesse dos alunos, com várias perguntas ao mesmo tempo, foram fundamentais na passagem do estranho para o familiar, já que podíamos trocar informações sobre gostos pessoais, preferências musicais, futebolísticas e orientação sexual. Respondíamos todas as perguntas até que o diálogo era encerrado quando a professora ou professor entendia que deveria retomar o controle da aula e ministrar o conteúdo do dia.

Esse artigo trata apenas de dados coletados em uma escola municipal, cujo nome não será divulgado a pedido da mesma, entretanto a pesquisa incluía ainda mais duas escolas de ensino fundamental. Embora a escola na qual se realizou a pesquisa se localiza entre um bairro considerado como habitado por uma população de classe média em Campo Grande, as informações obtidas junto a coordenação dão conta que a maior parte dos alunos moram em bairros da periferia da cidade.

"Nossos alunos são do Nova Lima, Jardim Colúmbia, Nova Bahia, Otávio Pécora e outros lugares perdidos aí da região norte da cidade. Não tem aluno aqui do bairro não. A maioria é pobre, temos também muitos alunos indígenas”. (Maria Coordenadora).

Essa conversa com a coordenadora do quinto ao nono ano ocorreu logo nos primeiros dias da pesquisa no pátio da escola, num tom informal. Ela estava acompanhada da professora de Geografia, que ouvia atentamente só interferindo quando interpelada. Indagamos a coordenadora sobre os alunos indígenas, qual etnia pertenciam, se ela percebia preconceitos contra os indígenas e se a escola tinha alguma política em relação a eles.

"Olha, não tem. Não sei a que tribo pertencem, o que a gente sabe aqui é que eles moravam com o pai. Mas ele morreu. Inclusive, eles nem perceberam que o pai morreu, eles contaram que o pai ficou vários dias morto na cama e eles não sabiam, 
até que apareceu um vizinho em casa e viu o que aconteceu. Eles continuam vindo na escola, mas não sabemos quem está cuidando deles não".

Apesar da perplexidade que tomou conta da equipe, continuamos o diálogo e numa outra passagem, a coordenadora revela que ela mesma já deixou um aluno indígena bastante constrangido.

"Tempos atrás entrei na sala do sexto ano para dar um recado e chamei atenção de um aluno que ficava o tempo todo puxando assunto com outro aluno. Oh japonês, para de conversar que estou falando. Ele começou a chorar, eu perguntei o porquê do choro, ele disse que eu chamei ele de japonês, fiquei sem entender, ai ele disse que não era japonês, era índio. Falei pra ele, então não sei porque você está chorando, é ser confundido com japonês, eles são estudiosos, inteligentes e sempre tiram nota boa na escola".

Ao término do relato, a professora de Geografia deu uma piscadela em nossa direção e interveio, explicando que o aluno havia chorado porque poderia ter se sentido ofendido com a confusão, não necessariamente por ter sido chamado de japonês, mas pelo fato da coordenadora da escola não saber que ele era indígena.

Passado esse momento, fomos observar a aula de Educação Física do $5^{\circ} \mathrm{B}$ na quadra da escola. A temática do bullying foi tratada. O professor fazia uma exposição sobre o tema e os alunos desenvolveriam uma redação ao final. Algumas destas redações foram disponibilizadas pelo professor para que pudéssemos ler, ao final ele disse que poderíamos reproduzir parte da redação, desde que a identidade do aluno não fosse revelada. A atividade se estruturava da seguinte maneira:

O que é o Bullying?

É uma agressão física, verbal ou psicológica que um indivíduo ou grupo pratica contra uma pessoa por algum motivo que impossibilita este de alguma defesa. É uma agressão repetitiva e constante.

A redação deveria abranger as seguintes questões:

O que você aprendeu sobre o bullying? Você já sofreu bullying? Já praticou? O que acontece com quem pratica? E com quem sofre? Apesar do tema do bullying ter sido tratado, se percebe na fala do professor e nas redações dos alunos, a invisibilidade de temas relacionados ao gênero e a sexualidade.

Em geral, as aulas de Educação Física funcionavam numa lógica de punição e recompensa, na qual os alunos que não se comportavam perdiam minutos desta aula ou eram obrigados a ficar em sala de aula, em vez de ir para a quadra com os colegas. Os exercícios de recreação realizados nesta turma eram feitos de forma mista, por vezes organizando os alunos de maneira heteronormativa, em casais de menino e menina. Na última parte da aula o professor costumava liberar as bolas para que os alunos pudessem jogar livremente. Os meninos decidiram jogar futebol e isso se repetiu em outros dias observados, apenas um garoto se absteve das atividades físicas e um grupo grande de meninas fez uma roda e começaram a jogar bola com as mãos entre elas, já que a única quadra estava ocupada com o jogo de futebol dos meninos.

Interessante que as atividades esportivas masculinas, como o jogo de futebol, os meninos têm sempre a preferência em usar a quadra, ao menos no período observado. Sempre coube às alunas a realização de atividades fora da quadra, sempre em suas margens. 
A divisão genereficada das atividades esportivas decorre da posição que homens e mulheres ocupam na estrutura social. Podem ser as escolhas de cores e roupas, brinquedos, a divisão de tarefas domésticas, a posição na hierarquia familiar e da sociedade como um todo; o grau de liberdade sexual, entre tantos outros aspectos da vida cotidiana de mulheres e homens são diretamente afetados por construções sociais que lhe ditam o que lhe é lícito e ilícito, apropriado e inapropriado, decente e indecente, sendo ele do sexo masculino ou do sexo feminino. A categoria gênero aqui utilizada se refere ao discurso sobre a diferença dos sexos. Essa concepção se remete às ideias, mas também a instituições, estruturas, práticas cotidianas e aos rituais, ou seja, a tudo aquilo que constitui as relações sociais (SCOTT, 1995, p. 15)

Outro aspecto observado nas atividades esportivas, diz respeito à noção social de masculinidade o que de certo modo, ajuda a compreender a construção a lógica de dominação não apenas dos homens sobre a mulheres, mas também entre os próprios meninos: "Eu sou melhor, eu ganho de você na porrada" e "Eu sou melhor, eu ganho de você jogando bola". Essas falas são comuns e são ditas constantemente, podendo se perceber a competitividade socialmente condicionada ao gênero masculino, bem como atividades estritamente masculinas como a luta, as brigas e o futebol. Uma das lutas mais comuns no ambiente escolar é a queda de braço $^{5}$. A queda de braço serve como uma exibição de potência corporal e masculinidade, é uma forma para exibir os músculos dos braços, ocorrendo, sobretudo entre os alunos de mais idade, entre 13 e 15 anos. Em um desses momentos da luta de braço, um aluno flexionou o braço exibindo seus músculos ainda em formação para o público. Um outro aluno do grupo o chamou de "gostoso", talvez porque apenas quisesse sociabilização, mas foi sonoramente vaiado pelos demais colegas, que o deixaram um pouco constrangido, embora não tenha sido agredido ou ofendido verbalmente. As vaias dos demais garotos pode representar a repreensão de uma fala não aceitável num grupo de homens que se pretende como heterossexual. Há um senso comum que homens não podem elogiar os dotes físicos de outro e menos ainda, admirar sua beleza. A partir disso, percebemos que a masculinidade naquele ambiente é cultivada e exercida através de coerção, ridicularização e ou até de uma certa forma de violência, especialmente contra os mais fracos ou aqueles considerados menos viris que, por vezes, não faziam parte destas rodas de sociabilidade.

Essas ocorrências via de regra, passam despercebidas pelos professores e coordenadores. Abaixo listamos algumas para ilustrar um pouco o cotidiano do ambiente escolar:

- $\quad$ É comum entre os meninos, também, a mudança do nome por sua versão feminina. Numa observação realizada durante a aula de matemática numa das séries, um aluno de nome Cauã, não conseguindo responder a tabuada corretamente recebeu a seguinte observação de um colega: "Você é ruim hein, Cauanny". Era comum também os alunos que tivessem o nome de Gabriel serem chamados pelos colegas de "Gaybriel" ou Gabriela, sobretudo quando não conseguiam executar uma tarefa em sala de aula como o esperado.

${ }^{5}$ A luta de braço (também conhecida como braço de ferro, quebra de braço ou queda de braço) é uma atividade esportiva em que dois contendores, com um dos cotovelos apoiados sobre superfície horizontal, enlaçam as mãos ou os punhos, e cada um, aplicando força muscular, tenta fazer o adversário desdobrar o braço. No Brasil existe é um esporte organizado pela Confederação Brasileira de Luta de Braço e Halterofilismo. www.cblbh.com.br 
- Durante a aula de Educação Física praticada somente pelos garotos enquanto jogavam queimada, pela dinâmica da brincadeira, começaram a se empurrar, e um deles não gostou e disparou "Cê é louco? Seu viado!" Chamar o outro de "Viado" é um modo comum de xingar uns aos outros, e muito recorrente no contexto da aula de Educação Física, sendo observado também entre os alunos de outras séries. Indicar o outro como sendo homossexual é uma forma de ridicularizar e inferiorizá-lo frente aos demais.

- $\quad$ Numa aula de português, os alunos de uma das séries planejavam fazer camisetas personalizadas para a sala, como é de costume nas séries finais do ensino médio e do fundamental. A professora disse: "As camisetas estilo Baby Look são só para as meninas". Ao escutar murmúrios vindos da sala completa "Uai, vocês vão querer vestir os meninos com camiseta baby look também?!"

- Após o intervalo os alunos costumam fazer fila na quadra para ouvir os informes da coordenação e organizar a volta para a sala. As filas são formadas de acordo com a turma e o gênero (ou sexo biológico, nesse caso). Uma das coordenadoras, que se colocava à frente das filas - que se organizavam em formação quase militar - perguntava em voz alta: "Mas o que é que Fulano está fazendo na fila das meninas?". Isso causou uma gargalhada geral.

- Na lista de chamada os alunos eram identificados por um número a partir de um (1) em ordem alfabética. Em algumas salas, coincidiu do número 24 pertencer a um garoto, nesse caso, sempre ocorria um comentário de outros garotos: “Vai lá, 24!”. O número 24 representa o Veado no jogo do bicho, sendo sempre associado pejorativamente a homossexualidade, também conhecido no imaginário social como viado.

- $\quad \mathrm{Na}$ aula de Artes, a professora orienta os alunos para que façam uma releitura da obra de arte cubista “As senhoritas de Avignon”, de Pablo Picasso. Um dos rapazes pergunta se em vez de mulheres poderia inserir outro elemento em sua releitura. "Professora, em vez das mulheres eu poderia desenhar...". Sua frase foi interrompida antes de ser concluída. Foi alvo de zoações por parte de outros alunos, um deles performando o estereótipo do aluno popular, hétero e esportista, que costuma fazer piadas sobre os outros demais, disse: “Ele quer desenhar veados, é todo bichinha, professora!", ele disse. A professora apenas disse que os animais não poderiam ser desenhados por conta do estilo da obra, embora tenhamos ficado sem saber o que o aluno queria desenhar já que ele, constrangido pelo comentário do colega, não terminou sua indagação.

A partir disso pode-se perceber que no mundo masculino já na infância e início da adolescência, os afetos e as emoções são considerados um sintoma de debilidade e indícios de uma virilidade insuficiente, por isso repreendido pelos demais. O homem, investido com os atributos do herói, deve conter as emoções já que estas afetariam o êxito em sua jornada, ainda que hoje essa aventura não consista em matar dragões e em salvar as princesas, mas sim em liderar iniciativas, obter maior salários, em ser empreendedor e a ascender na escala social. A tirania desse modelo dominante de masculinidade tem efeitos indesejáveis, não somente para as mulheres que sofrem com a violência de gênero, resultante dessa masculinidade agressiva e injusta, nas afeta também aos homens, como assinala Kaufman (1997, p. 67), cada vez mais, os homens sentem a dor de ter que assumir padrões impossíveis de virilidade, que resultam em vivências reprimidas de afetos e desejos, mas que se expressam em situações de agressividade e violência em muitas áreas da vida social. 
Além disso, a problemática se encontra não apenas no despreparo dos professores e coordenadores, mas também na dificuldade em se lidar com o tema num contexto social e político que reforça o preconceito contra LGBTQIs, tanto na escola quanto em relação aos pais dos alunos. O Plano Municipal de Educação não contempla o tema da diversidade sexual e há projeto de lei na Câmara Municipal que propõe punir o professor que o abordar em sala de aula.

\section{A violência escolar: A invisibilidade do bullying homofóbico}

A violência no contexto escolar investigado está historicamente vinculada muito mais a atos de roubo, brigas entre alunos e agressões verbais sem incluir o dano emocional que pode implicar em outros tipos de manifestações violentas. A escola é descrita como um lugar pacífico, livre dos roubos, brigas e agressões. Em conversa com um dos professores de Educação Física, indagamos se ele percebia a existência de bullying entre os alunos:

"Isso eu não vejo aqui, até porque sempre eu falo pra eles assim: Eu gosto do respeito!" Então, assim, o que eu quero. Respeito todos de igual pra igual e exijo que me respeitem e se respeitem! É isso o que eu sempre falo pra eles".

No entanto, percebe que existem muitas brincadeiras entre os alunos, que envolvem a troca de apelidos e gozações, principalmente entre os meninos. Não classifica estas brincadeiras como bullying, mas encaminha os alunos envolvidos para a orientação quando as coisas saem do seu controle ou quando algum aluno reclama. Mas, percebemos que entre os alunos, o próprio professor foi algumas vezes alvo de piadas envolvendo frases do tipo "Nossa, que bofe lindo!" sempre ditas de maneira jocosa. Embora não tenhamos especulado sobre sua sexualidade, os alunos o identificam como homossexual deixando sempre escapar brincadeiras e frases que fazem menção a sua orientação sexual.

A escola ao longo dos últimos cinco anos, tem realizado ações internas e parcerias para a realização de palestras e oficinas com os alunos para conscientização e redução do número de ocorrência de casos de violência entre os alunos. O tema do bullying de um modo geral tem sido negligenciado ou restrito a algumas atividades e apresentações avaliativas, entre outras, segundo relato de uma das coordenadoras:

"Eu até vejo que ultimamente tem umas iniciativas boas. Olha, agora chegou uma coleção do Içami Tiba e tem uns 20 vídeos em cada caixa... são três caixas. Tem aqueles livros "Quem ama educa" e outros que ele já lançou. Estão aqui na biblioteca, disponíveis para empréstimos para os pais, mas até agora não veio nenhum pegar. Então esses DVDs, cada um deles, o Içami Tiba é entrevistado, na forma de perguntas e respostas. São muito bons mesmo. E é aí que a gente vê que essas iniciativas são boas porque vão trabalhando a formação dos pais. Olha, muitas coisas. Volta e meia vem o promotor, o Harfouche, Dr. Sérgio Harfouche. Tem outro convidado também que tem vindo o Juiz, Dr. Odilon. E essas ações que, assim, diretamente não estão relacionadas com essa questão de bullying, mas como trabalham o respeito às normas, né? A aceitar certas "coisas" do outro... Não revidar. O DETRAN... Questão de cidadania com a Solurb, reciclagem. É um trabalho que vai além da mera reciclagem, reaproveitamento de material. O PROERD é ótimo!" 
O PROERD é, segundo informações do site "PROERD Brasil" é o Programa Educacional de Resistência às Drogas. Na verdade, a ação do programa nesta escola consistiu em um projeto no qual, policiais militares, fardados, devidamente treinados e com material próprio (livro do estudante, camiseta e diploma) desenvolveram um curso de prevenção às drogas e a violência na sala de aula. Na escola pesquisada o bullying foi uma das temáticas trabalhadas pelo programa, mas não envolveu o tema da violência homofóbica.

O debate sobre temas que envolvem gênero, sexualidade e homofobia no ambiente da escola é obstaculizado por vários motivos: A idade dos alunos, o controle das informações exercido pela instituição, pela pressão que os responsáveis da escola impõem sobre alunos e professores e principalmente porque não aparece como um problema na visão da comunidade escolar.

Questionada se as temáticas de gênero e sexualidade eram incluídas no planejamento das atividades sobre o bullying na escola, uma das coordenadoras expõe a sua opinião:

"É um tema, assim, meio delicado inclusive né, porque a gente tem que saber como falar. E nesse sentido também a gente trabalhou aqui na escola com palestras sobre sexualidade e orientações sexuais. Porque os meninos do sexto ano em diante, de uma maneira geral, eles já estão no despertar da sexualidade. É o início da adolescência, início da descoberta, o início assim, de despertar ao sexo oposto... E são nesses momentos é que a gente observa, de repente, um comportamento... Ou de uma menina, ou de um menino que está assim... Eu digo desvio de comportamento! Porque não deixa de ser. Sabe, porque por mais que cada um faça sua escolha sexual, vamos dizer assim, biblicamente a gente sabe que não é um comportamento normal de uma pessoa. Envolve aí, eu sei, vários fatores.... Desde a questão familiar, de orientação sexual mesmo, e de referências. Referência: A mulher tem que ter uma referência masculina para ela se auto afirmar enquanto mulher. Enquanto o rapaz tem que ter uma referência feminina para ele se auto afirmar enquanto homem. Não é? Porque é o Complexo de Édipo, né? Que nós dizemos por aí: O menino tem mais afinidade com a mãe, e a menina tem mais afinidade com o pai. Geralmente é assim. E quando isso não acontece, muitas vezes, não é bem trabalhado.... Acontece aí então os desvios comportamentais.

P: E, por acaso, aparece um aluno reclamando de algo relacionado a isso, vocês costumam orientar, prestar algum atendimento?

E: Sim, a gente faz... De uma certa forma, assim, aqui dentro da escola a gente orienta nesse sentido: Aqui dentro da escola é um ambiente escolar, é para estudar! Outras coisas que, de repente, você faz a sua opção e quer segui-la e não tá conforme os padrões da sociedade, porque também tem essa questão, né? Nós pedimos pra ter uma postura condizente com o lugar".

Essa coordenadora costuma expor com frequência seus pontos de vista destacando seus valores e noções de ordem e civilidade, que tenta passar aos alunos que por ventura sejam encaminhados à coordenação. Sobre homossexualidade, ela tem uma posição que trouxe da religião para escola. Além de considerar a homossexualidade e outras questões de gênero como "desvios comportamentais" e "biblicamente anormais", ela valoriza o papel da religião no processo educacional:

"P: E uma última coisa: Eles costumam rezar sempre? Percebi que eles sempre fazem filas após o intervalo. Às vezes é o hino e às vezes eles rezam.

${ }^{6}$ http://www.proerdbrasil.com.br/oproerd/oprograma.htm 
E: Uma vez por semana a gente tem o hino e uma oração. No início tivemos uma época que fazíamos todos os dias. Mas aí solicitaram que poderia ser apenas uma vez por semana, daí diminuímos.

P: E quem fez essa solicitação? Foram pais de alunos?

E: Olha, é até uma história, sabe? Porque os pais gostam. Por outro lado, tem uns que não gostam. Aí depois dizem que surgiu um decreto, uma legislação aí que era pra ser feito todo dia na escola. Mas depende muito da organização da escola. Tem escola que faz, tem escola que não. É importante que se tenha o momento cívico, mas infelizmente foi tirado o ensino religioso das escolas. Eu vejo que o ensino religioso seria, a meu ver, não para se trabalhar doutrinas, religião, isso e aquilo outro; mas a vivência do dia a dia de cada um. Porque é o que eu falo: O respeitar não é na hora que eu quero, como eu quero, onde eu quero, da forma que eu quero. O egoísmo tem de ser tirado. Então tinha que ser trabalhado, a meu ver enquanto pessoa. Trabalha o que é o egoísmo, o que é solidariedade, porque é que se deve agir de tal forma, sabe? A vivência diária de cada um, porque Deus é importante na nossa vida. De uma maneira geral, sem se ater a religião nenhuma. É o que eu falo: Falar de Deus é uma coisa; falar da bíblia e praticar é outra! Porque religião são todas, mas praticar o cristianismo! Porque ele é único. É uma coisa que é do nosso dia a dia. De aprendizagens que a gente pode crescer através de exemplos, de ações, de respeito mútuo, fraternidade, solidariedade, entre outras tantas coisas que Jesus pregou".

Mesmo sem oferecer a disciplina de Ensino Religioso, essa escola, assim muitas instituições usam religião no dia a dia. Segundo respostas dadas por 54.434 diretores ao questionário da Prova Brasil $2011^{7}$, independentemente de oferecer a matéria, $51 \%$ das escolas cultivam o hábito de cantar músicas religiosas ou fazer orações no período letivo, no horário de entrada ou da merenda, entre outros. A escola pública, embora laica, se utiliza em maior escala da religião como estratégia de educação moral, entendendo ser a religião uma ferramenta preciosa na formação geral do aluno. (LIMA, 2009, p. 236)

Para além da fala da coordenadora, o discurso religioso permeia o dia a dia dos estudantes, sendo usado para solucionar casos de indisciplina e de conflitos. Observamos também que alguns professores diziam aos estudantes frases como "Deus castiga os desobedientes". Ainda se pôde notar em várias partes da escola como murais, na sala de informática e nos banheiros, cartazes com variados trechos bíblicos e frases de Chico Xavier, exaltando a obediência, a disciplina e a paz.

As práticas cotidianas da escola cria a invisibilidade do bullying homofóbico presente na fala dos alunos e da coordenação, ou seja de todos os usuários do sistema de educação, quanto posto que este tipo de preconceito, discriminação e violência estão fortemente enraizados nas práticas cotidianas desses atores sociais, práticas alicerçadas nas representações, nos valores, nas crenças que possuem acerca da diversidade sexual e de gênero que naturalizam a heteronormatividade e a negação às outras formas de expressão da sexualidade.

Pode-se perceber que o processo de homofobia nas escolas, diz respeito às crianças e jovens vítimas desse preconceito, que se invisibilizam pelo silêncio e pelo medo, ante o constrangimento público que se dá

${ }^{7}$ Brasil, Ministério da Educação. http://portal.mec.gov.br/prova-brasil/simulado-prova-brasil-2011. Acesso em 24/09/2018 
por meio de insultos, agressões disfarçadas de brincadeiras promovidos pelos colegas de escola. A homofobia quando sentida e aceita pode ser interiorizada como vergonha de si mesmo, aprisionando, fazendo com que os homossexuais se escondam e se tornem invisíveis para não serem identificados como tal. E quando interiorizam e "aceitam" essa discriminação e preconceito, por medo, insegurança ou sentimento de inadequação, também estão se submetendo a uma situação de subordinação e violência, o que faz com que sintam culpa e vergonha de si mesmos, atingindo contundentemente suas subjetividades, gerando medos de não serem apropriados, bem como sentimentos de submissão, insegurança e vulnerabilidade, elementos que irão contribuir para a manutenção da heteronormatividade.

\section{Considerações finais}

Nesta pesquisa, foi possível observar que a principal forma de reprodução da heteronormatividade no ambiente escolar em questão é através de brincadeiras, xingamentos e chacotas. Assim, apesar de serem consideradas inofensivas por estarem em tom jocoso, as brincadeiras se mostram como uma forma de violência homofóbica.

Importante ressaltar que esta violência não foca apenas a LGBTQIs, pois essas violências se dirigem a todos e todas, apenas em graus diferentes, assim como é importante não criar vítimas e algozes na reflexão, pois todos os sujeitos estão submetidos às normas heterossexistas. Por todos estarem sob a imposição da heteronormatividade, tanto hétero quanto homossexuais reproduzem esta norma.

Embora possa se perceber a existência de LGBTQIs, não vimos nenhum aluno declaradamente gay, travesti, transexual ou lésbica ou de qualquer outra orientação sexual ou gênero diversos à heteronormatividade, talvez em razão da idade, sendo ainda crianças e pré-adolescentes em sua maioria, mas também há de se considerar que o ambiente escolar é bastante hostil, fato este observado em outra pesquisa com alunos já entre 15 e 18 anos, cursando o ensino médio em outra escola pública da cidade. Do mesmo modo, há alunos de diferentes orientações sexuais e de gênero, mas que não se sentem inseguros quanto a assumirem a sua sexualidade ou identidade de gênero devido toda violência verbal, simbólica e/ou física que podem sofrer. Assim, pode também haver alunos de sexualidades e gêneros considerados dissidentes que não aceitam sua própria orientação devido à reprodução de brincadeiras homofóbicas que, enquanto alguns consideram como uma simples brincadeira, outros podem se sentir ofendidos e preferir a invisibilização ("sair do armário") por receio da repressão que possam vir a sofrer, inclusive dentro do ambiente escolar, considerado por alguns alunos como "pacífico", afinal, o ato de "sair do armário" não se resume apenas a "se assumir" (ir de dentro para fora), mas é necessário sair de vários "armários", pois o aluno deverá se assumir para os pais, para os colegas, para os professores, entre outros, num esforço constante de demonstração de orgulho e reconhecimento.

Há ainda o despreparo e o receio dos educadores em tratar de temas como gênero e sexualidade. Em casos relatados, professores e coordenadores reproduzem o preconceito e demonstram recusa em discutir temas 
considerados delicados por eles, devido também ao contexto que foram formados e educados, colocando que oficinas de discussão sobre gênero e sexualidade devem ser feitas apenas com alunos.

Torna-se um grande desafio para educação subverter esta heteronormatividade, não se tornando apenas um agente passivo da norma, se repensar e se transformar de modo que não exclua os diferentes grupos subalternizados para que evite estes contextos de violência verbal, física, psicológica, simbólica, entre outros.

\section{Referências}

ALBUQUERQUE. Paloma Pegolo.; WILLIANS, Lúcia Cavalcanti de Albuquerque. Homofobia na Escola: Relatos de Universitários sobre as Piores Experiências. Trends in Psychology / Temas em Psicologia, Ribeirão Preto, Vol. 23, nº 3, 663-676, set. 2015.

BRASIL, Ministério da Educação. http://portal.mec.gov.br/prova-brasil/simulado-prova-brasil-2011. Acesso em 24/09/2018.

BRASIL. Lei 13.005/2014, 25 de junho de 2014. Plano Nacional de Educação. www.planalto.gov.br . Acessado em 20 de julho de 2018.

CASTRO, Paula Almeida de. Tornar-se aluno: identidade e pertencimento a um estudo etnográfico. Tese (Doutorado em Educação) - Faculdade de Educação, Universidade do Estado do Rio de Janeiro, Rio de Janeiro, 2011. Disponível em: http://www.proped.pro.br/teses/teses_pdf/2004_1-74-DO.pdf. Acesso em: 11 de setembro de 2018

DE OLHOS NOS PLANOS. Disponível em: http://www.deolhonosplanos.org.br/. Acesso em 03/09/2018.

DINIS, Nilson Fernandes. Homofobia e educação quando a omissão também é signo de violência. Educ. rev., Curitiba, n. 39, abril de 2011.

FUNDAÇÃO PERSEU ABRAMO. Disponível em www.fpabramo.org.br. Acessado em 05 de julho de 2011.

G1. Após polêmica, plano de educação é sancionado em Campo Grande. Disponível em: http://g1.globo.com/mato-grosso-do-sul/noticia/2015/06/apos-polemica-plano-de-educacao-e-sancionadoem-campo-grande.html. Acessado em 26 de agosto de 2018.

FIPE. Relatório final. Disponível em http://portal.mec.gov.br/dmdocuments/relatoriofinal.pdf. Acesso em $28 / 09 / 2018$

FOOTE-WHYTE, William. Treinando a observação participante. In: GUIMARÃES, Alba Zaluar. (org.). Desvendando máscaras sociais. Rio de Janeiro: Francisco Alves, 1975, pp.77-86.

FORMBY, Eleanor. Limitations of focussing on homophobic, biphobic and transphobic 'bullying' to understand and address LGBT young people's experiences within and beyond school. Sex Education 15 (6), p. 626-640. Jul. 2015

FURLONG, Micheal.; SHARKEY, Jill.; FELIX, Erika D.; GREIF-GREEN, Jenifer. Bullying assessment: A call for increased precision of self-reporting procedures. The international handbook of school bullying. editado por Shane Jimmerson, Susan Swearer e Dorothy Espelage: Routledge, 2010.

HABERMAS, Jurgen. O Estado-Nação europeu frente aos desafios da globalização. Novos Estudos Cebrap. 1995, p 43, 87-101. 
INEP. Instituto Nacional de Pesquisas Educacionais Anísio Teixeira. Prova Brasil, http://portal.mec.gov.br/dmdocuments/prova\%20brasil_matriz2.pdf. 2011. Acesso em 18/09/2018.

JUNQUEIRA, Rogério Diniz. Homofobia nas escolas: um problema de todos. In: JUNQUEIRA, Rogério Diniz. (org) Diversidade Sexual na Educação: problematizações sobre a homofobia nas escolas. Brasília: UNESCO, 2009. p 13-51.

KAUFMAN, Michael. Las experiencias contradictorias del poder entre los hombres. In: VALDÉS, Teresa; OLAVARRÍA, José. (Eds.) Masculinidades: poder y crisis. Santiago de Chile: Isis Internacional-Flacso. 1997. p. 63-81.

LIMA, Aline Pereira. O uso da religião como estratégia de educação moral em escolas públicas e privadas de Presidente Prudente. Nuances: estudos sobre Educação. Presidente Prudente, SP, ano XV, v. 16, n. 17. p 235-236. jan. /dez. 2009.

LOURO, Guacira Lopes. Currículo, gênero e educação. Porto Alegre: Porto Editora, 2001.

MALINOWISK, Bronisław. Os argonautas do Pacífico Ocidental. São Paulo: Abril Cultural, 1976.

MATO GROSSO DO SUL (Estado). Lei 4.621 de 22 de dezembro de 2014. Plano Estadual de Educação. Disponível em: http://www.sed.ms.gov.br/wp content/uploads/sites/67/2015/05/pee-ms-2014.pdf. Acesso em $06 / 09 / 2018$

MEYER, Elizabeth J. A feminist reframing of bullying and harassment: Transforming schools through critical pedagogy. McGill Journal of Education, 43 (1). p 33-48, inverno 2008.

MINTON, Stephen J.; DAHL, Torunn.; O' MOORE, Astrid M. ; TUCK, Donnely. An exploratory survey of the experiences of homophobic bullying among lesbian, gay, bisexual and transgendered young people in Ireland. Irish Educational Studies 27 (2), p 177-191, 2008.

MONK, Daniel. Challenging homophobic bullying in schools: the politics of progress. International Journal of Law in Context 7 (2), p 181-207, 2012

NOGUEIRA, Conceição.; OLIVEIRA, João Manoel. Estudo sobre a discriminação em função da orientação sexual e da identidade de género. Lisboa: Comissão para a Igualdade de Género. Disponível em http://www.igualdade.gov.pt/images/stories/documentos/ documentacao/publicacoes/Estudo_OrientacaoSexual_IdentidadeGenero.pdf. 2010.

PASCOE, C. J. 2013. Notes on a sociology of bullying: Young men's homophobia as gender socialization. QED: A Journal in GLBTQ Worldmaking 1, 2013, p 1-18.

PROERD. PROERD no Brasil. Disponível em: http://www.proerdbrasil.com.br/. Acessado em agosto de 2018

ROSELI-CRUZ, Amadeu. Homossexualidade, homofobia e a agressividade do palavrão. Seu uso na educação sexual escolar. Educar em Revista, Curitiba, Brasil, n. 39, p. 73-85, jan. /abr. 2011. Editora UFPR.

SCOTT, Joan. Gênero: Uma categoria útil de análise histórica. Educação e Realidade. V 20, n 2, 1995.

SILVA, Maria Oneide L.; et al. Etnografia e pesquisa qualitativa: apontamentos sobre um caminho metodológico de investigação. In: Encontro de pesquisa em

Educação, 6., Teresina, PI. Anais...Teresina, PI: UFPI, 2010. Disponível em:

http://www.ufpi.br/subsiteFiles/ppged/arquivos/files/VI.encontro.2010/GT.1/GT 01 15 .pdf .Acesso em: 11 de setembro de 2018. 
SOUZA, Jaqueline Maria.; FARO, André; SILVA, Joilson Pereira. Bullying e Homofobia: Aproximações Teóricas e Empíricas. Psicol. Esc. Educ. vol.19 no. 2 Maringá May/Aug. 2015.

UNESCO. Review of homophobic bullying in educational institutions. Disponível em: http://unesdoc.unesco.org/images/0021/002157/215708e.pdf. 2012.

VIANNA, Claudia Pereira. O movimento LGBT e as políticas de educação de gênero e diversidade sexual: perdas, ganhos e desafios. Educ. Pesqui., São Paulo, v. 41, n. 3, p. 791-806, jul./set. 2015

ZARBATO, Jaqueline Ap. M.; QUEIRÓZ, Vivina Dias Sol. Reflexões sobre estudos de gênero no Plano Municipal de Educação de Campo Grande/MS e os diálogos com a história ensinada. Fronteira; Revista de História, v. 19, n. 34,. p. 373-388, Dourados, jul-dez 2017.

\section{Recebido em: 01/06/2021}

Aprovado em: 25/06/2021

Publicado em: 30/06/2021 